\title{
CONTROVÉRSIAS SOCIOCIENTÍFICAS E O ENSINO POR INVESTIGAÇÃO: UMA ESTRATÉGIA DIDÁTICA PARA AUXILIAR NO DESENVOLVIMENTO DE HABILIDADES PROPOSTAS PELA BASE NACIONAL COMUM CURRICULAR
}

\section{Socio-scientific controls and research teaching: a teaching strategy to assist in the development of skills proposed by Base Nacional Comum Curricular}

\author{
Alexandre Rodrigues da Conceição ${ }^{1}$ \\ Elton Casado Fireman ${ }^{2}$
}

\begin{abstract}
Resumo: A compreensão de que a sociedade é cada vez mais influenciada pela Ciência e pela Tecnologia nos faz refletir sobre a importância da formação de cidadãos que sejam capazes de lidar com problemas científicos e tecnológicos. Dessa forma, o Ensino de Ciências da Natureza precisa ser planejado para o desenvolvimento de habilidades que contribuam para o exercício da cidadania. Buscamos, então, responder à seguinte questão de pesquisa: quais habilidades o alunado precisa desenvolver, ao longo da educação básica, de acordo com a Base Nacional Comum Curricular (BNCC)? Nesse sentido, o objetivo dessa pesquisa é analisar a BNCC, frente a assuntos que envolvem controvérsias de cunhos sociais e científicos. Decidiu-se, pois, pela via do ensino por investigação, como abordagem didática. Essa pesquisa possui um enfoque qualitativo, quanto ao procedimento, no uso da pesquisa documental. Diante dos dados coletados, foi realizada a análise do conteúdo proposto por Bardin (1977). Os resultados evidenciam que a BNCC preza pelo desenvolvimento de habilidades que contribuam para a formação de cidadãos capazes de resolver problemas, tomar decisões, fazer escolhas e transformar a sua realidade, a partir do saber científico. E, diante das propostas da BNCC, observou-se uma possibilidade de trabalhar questões polêmicas, de forma interdisciplinar, uma maneira integrada de compreender os desacordos sociocientíficos, em suas diferentes dimensões.
\end{abstract}

Palavras-chave: Ciências da Natureza. Ensino de Ciências. Propostas curriculares.

Abstract: The understanding that society is increasingly influenced by Science and Technology makes us reflect on the importance of training citizens who are able to deal with scientific and technological problems. Thus, the Teaching of Natural Sciences needs to be planned for the development of skills that contribute to the exercise of citizenship. We seek, then, to answer the following research question: what skills does the student need to develop, throughout basic education, in the area according to the National Common Curricular Base (BNCC)? In this sense, the objective of this research is to analyze the BNCC, in the face of issues that involve controversies of social and scientific nature. It was decided, therefore, through teaching by investigation, as a didactic approach. This research has a qualitative focus, regarding the procedure, in the use of documentary research. In view of the data

\footnotetext{
${ }^{1}$ Mestre em Educação e Licenciado em Ciências Biologias pela Universidade Federal de Alagoas. Orcid: https://orcid.org/0000-0002-6405-2286. E-mail: allexandrebcp@ @otmail.com

${ }^{2}$ Doutor em Física e professor da Universidade Federal de Alagoas (UFAL), atuando nos Programas de PósGraduação em Educação e de Ensino de Ciências e Matemática. Orcid: https://orcid.org/0000-0002-2570-7841. E-mail: elton@cedu.ufal.br
} 
collected, an analysis of the content proposed by Bardin (1977) was carried out. The results show that BNCC values the development of skills that contribute to the formation of citizens capable of solving problems, making decisions, making choices and transforming their reality, based on scientific knowledge. And, in view of the BNCC proposals, there was a possibility of working on controversial issues, in an interdisciplinary way, an integrated way of understanding socio-scientific disagreements, in their different dimensions.

Keywords: Natural Sciences. Science teaching. Curricular proposals.

\section{Introdução}

O Ensino de Ciências da Natureza, voltado para a memorização de conceitos, reprodução de teorias e distante da realidade, além de se tornar desinteressante, contribui para o desenvolvimento de visões distorcidas da Ciência (GIL-PÉREZ et al., 2001). Por isso, as discussões sobre um Ensino voltado para a construção de conhecimentos, úteis para a vida, vem ganhando novas proporções (GALVÃO; REIS; FREIRE, 2011).

Destarte, o saber científico deve estar cada vez mais próximo do cotidiano, buscando ajudar na compreensão e resolução de problemas científicos, presentes na relação Ciência, Tecnologia, Sociedade e Meio Ambiente (CTSA) (MARTÍNEZ-PÉREZ, 2012). A utilização de contendas, na área, vem sendo destacada como uma possibilidade para despertar o interesse para esses conteúdos, já que, na maioria das vezes, são tópicos problematizados, portanto mais próximos da realidade (DUSO, 2017).

Desse modo, a formação de cidadãos críticos e reflexivos, capazes de transformar a realidade em que se inserem, necessita estar voltada para promover tais habilidades, como uma real contribuição. Buscamos, para tanto, responder à seguinte questão de pesquisa: quais habilidades os estudantes precisam desenvolver, ao longo da educação básica, na área de Ciências da natureza, de acordo com a Base Nacional Comum Curricular (BNCC)?

O objetivo desse estudo consiste em analisar as habilidades que os discentes precisam desenvolver, em assuntos contestáveis, propostos pela Base Nacional Comum Curricular (BNCC) (BRASIL, 2018), por meio de uma pesquisa documental (PÁDUA, 1997). Eis, então, a possibilidade de realização de ensino/pesquisa, como uma abordagem didática capaz de auxiliar no seu desenvolvimento.

\section{Ensino por investigação e controvérsias sociocientíficas: ressignificando o Ensino de Ciências}

O cenário escolar, reflete a necessidade de superarmos alguns obstáculos. Dentre eles, podemos destacar o senso comum pedagógico (CARVALHO; GIL-PÉREZ, 2011; DELIZOICOV; ANGOTTI; PERNAMBUCO, 2018). Ao abraçar essa visão de ensino, as estratégias didáticas utilizadas pelos professores não têm contribuído para que os discentes aprendam a Ciência que lhes é ensinada (POZO; CRESPO, 2009), em virtude do distanciamento da realidade.

Para Delizoicov, Angotti e Pernambuco (2018), o senso comum pedagógico está ligado à compreensão de que a aprendizagem ocorre por meio da transmissão-recepção, resultado do processo formativo dos professores (CARVALHO; GIL- PÉREZ, 2011). Como consequência dessa concepção, destacam-se suas escolhas metodológicas. E, buscando contribuir com a melhoria da qualidade, apontamos o ensino por investigação, para o 
desenvolvimento de atividades que aproximam o fazer científico à sociedade vigente. (CARVALHO, 2013; SASSERON, 2015).

Segundo Carvalho (2013), essa formulação possui como objetivo tornar a sala de aula um ambiente investigativo, sendo o aluno o protagonista e o professor o mediador, auxiliando no desenvolvimento de habilidades científicas, como o levantamento e teste de hipóteses, registro de dados, comunicação de seus achados, em confronto com as teorias já comprovadas.

Ao realizar estudos sobre as pesquisas desenvolvidas por Piaget (1974) e Vigotsky (1984), Carvalho (2013) compreende a importância de uma pergunta-problema e entende a necessidade de propiciar condições interativas, durante as aulas. Unindo esses elementos, Carvalho (2013) propõe uma Sequência de Ensino Investigativa (SEI).

Sasseron (2015, p. 59) define uma SEI como sendo "o encadeamento de atividades e aulas em que um tema é colocado em investigação e as relações entre esse tema, conceitos, práticas e relações com outras esferas sociais e de conhecimento possam ser trabalhados". Como se pode ver, uma SEI não se restringe a trabalhar um conteúdo de forma isolada, mas articulado com outras dimensões, sejam elas políticas, sociais ou ambientais.

A primeira etapa para dar início à SEI é a proposição de um problema, este não pode se restringir a uma simples pergunta. Precisa ser, suficientemente, motivador para incentivar os estudantes a investigarem, buscando sua resolução. Carvalho (2013), bem como Campos e Nigro (1999) reforçam a importância desse momento inicial, pois o engajamento com as próximas atividades dependerá da forma como o conteúdo a ser estudado foi problematizado.

Na segunda etapa, Carvalho (2013) destaca como sendo importante que o professor forneça materiais que possam ajudar na resolução da questão. Em seguida, os discentes levantam e testam suas hipóteses, eliminam as variáveis que possam estar influenciando a obtenção de uma solução e interagem com os colegas, até chegarem a um consenso. Para Carvalho (2013), nessa metodologia, a manipulação do objeto de estudo não é o fim da atividade; necessário se faz transitar da ação manipulativa para a ação intelectual. A próxima etapa é conhecida como sistematização do conhecimento, de forma coletiva e individual. Onde os alunos relatam suas ações durante as atividades, por meio da oralização, produção de textos e desenhos (CARVALHO, 2013).

Nessa metodologia, o planejamento possui particular relevância, para que o professor consiga alcançar os objetivos da aprendizagem. Carvalho (2011) estabelece oito pontos que são fundamentais para orientar a organização da SEI. Contudo, para esse estudo, destacaremos apenas o sétimo ponto que aborda a importância de inserirmos, na SEI, a relação Ciência, Tecnologia e Sociedade. A autora argumenta que "se nosso objetivo é introduzir os alunos no universo da Ciência as relações CTS devem estar presentes em todas as nossas SEIs" (CARVALHO, 2011, p. 259). Diante disso, a preocupação com a maneira como a relação Ciência, Tecnologia e Sociedade interage com o meio ambiente, despertou para a inserção da dimensão ambiental formando a sigla CTSA (MARTÍNEZ-PÉREZ, 2012).

A importância de inserirmos a relação CTSA nas aulas de Ciências se deve à necessidade de estabelecermos uma construção cultural e histórica, em suas aplicações na sociedade. Nesse contexto, o ensino precisa estar voltado para a formação de cidadãos capazes de compreender, argumentar e tomar decisões sobre assuntos que fazem parte dessa relação. Scarpa e Campos (2018) destacam que, por meio da investigação, podemos trabalhar algumas questões sociocientíficas que dividem opiniões e estão relacionadas às dimensões sociais da Ciência como: 
Vacinar ou não os filhos? Reduzir ou não o controle do uso de agrotóxicos? Consumir ou não alimentos transgênicos? Desastres ambientais, terapias gênicas, exames laboratoriais, teste de paternidade e toda a gama de novas tecnologias associadas ao DNA, combate a epidemias, questões de gênero e sexualidade e vegetarianismo são temas de interesse da população e que demandam algum conhecimento no âmbito das ciências biológicas para a sua compreensão e o seu julgamento de maneira informada (SCARPA; CAMPOS, 2018, p. 33)

Tomar decisões sobre as questões acima citadas, como parte do cotidiano, reforça a relevância da apropriação do saber científico, para a formação de cidadãos que desenvolvam um olhar crítico sobre o mundo. Por isso, Chassot (2018, p. 98) diz que uma das maiores responsabilidades ao ensinarmos Ciências é "procurar que nossos alunos e alunas se tornem, com o ensino que fazemos, homens e mulheres mais críticos. Sonhamos que, com o nosso fazer educação, os estudantes possam tornar-se agentes de transformação - para melhor - do mundo que vivemos". Diante dessa concepção, reafirma-se a urgência de renovação no Ensino de Ciências (CACHAPUZ et al., 2005).

Para isso, é importante uma reflexão sobre a forma como os professores concebem o que é e para que ensinar Ciências; resumir o ensino à reprodução de teorias, sem possibilidades de reflexão, pode reforçar as imagens distorcidas que ainda existem sobre a Ciência. De acordo com Martínez-Pérez (2012, p. 32), podemos encontrar dificuldades em ressignificar esse cenário, pelo fato de que as escolas continuam a tratar as Ciências como "uma atividade objetiva e não problemática, privilegiando a visão cientificista, que leva os alunos a aderir a racionalidade técnica, na qual o conhecimento científico é visto como verdade imutável e imune a questionamentos". Essas ideias também são compartilhadas por Gil-Peréz et al (2001), ao tratar de imagens distorcidas do trabalho científico.

Umas das possibilidades para superarmos este cenário é por meio da utilização de teorias científicas divergentes. As CSC são apontadas como uma possibilidade de construir a visão de uma Ciência que é controversa e constituída de interesses (BAZZO, 2002). Para Reis (1999), a inserção das CSC pode contribuir para tornar o espaço escolar um ambiente pautado na argumentação e reconstrução de ideias. Por meio dessa abordagem, os discentes são capazes de compreender as situações sociais, a ação humana e seus impactos. Contudo, discussões sobre conteúdos contestatórios, durante a prática docente, pode não ser tão simples como parece.

Martínez-Pérez (2012) reconhece que tratar essas questões é complexo, na medida em que algumas discussões podem envolver dimensões culturais, morais, éticos e religiosos que se complicam, devido ao saber docente instalado, na interligação de todas essas dimensões. Lickona (1991) contribui com esse contexto ao argumentar que os professores receiam trabalhar as CSC, alegando possível falta de controle da turma, dependendo do tópico abordado, o que somente comprova a incipiente formação pedagógica. $\mathrm{O}$ autor citado destaca, ainda, que esse temor, leva o professor a perder profícuas possibilidades de desenvolver importantes discussões.

Reafirmando a necessidade de inserir questões discordantes durante as aulas, Stenhouse (1970, apud Reis, 1999) destaca que, por meio do planejamento, o professor pode criar um ambiente pautado na discussão, fazendo uso de perguntas-problemas, estimulando a participação e permitindo que haja interação durante a reflexão. $\mathrm{O}$ autor ainda destaca que o professor poderá fazer uso da gravação de áudios e analisá-los, posteriormente, como uma forma de refletir sobre sua prática e, portanto, tentar aperfeiçoá-la. A proposta de Stenhouse (1970, apud Reis, 1999) possui uma ligação com o ensino voltado para a pesquisa apresentado por Carvalho (2013), ao tempo em que polemiza o conteúdo programático, preza pela participação e promove discussões coletivas. 
Sendo assim, tal método possui potencialidade para contribuir com a prática docente, na organização de atividades direcionadas a conteúdos próximos da realidade, ao desenvolver habilidades que deem lugar à desconstrução de uma Ciência rígida, aproblemática e ahistorica (GIL-PÉREZ, et al., 2001).

\section{O que diz a Base Nacional Comum Curricular (BNCC)}

Diante da do imperativo de trabalhar as divergências de opiniões científicas, é relevante conhecermos as propostas curriculares que orientam a prática docente para a área de Ciências da Natureza, presente na Base Nacional Comum Curricular (BNCC). A BNCC (BRASIL, 2018) argumenta sobre a necessidade da formação de cidadãos que compreendam o desenvolvimento da sociedade, marcada pela interferência da Ciência e da Tecnologia e suas aplicações, com possíveis consequências socioambientais. De acordo com a BNCC (BRASIL, 2018), os alunos precisam de uma formação que proporcione uma compreensão sobre conteúdos científicos voltados para o social, para que sejam capazes de tomar decisões conscientes sobre:

[...] alimentos, medicamentos, combustíveis, transportes, comunicações, contracepção, saneamento e manutenção da vida na Terra, entre muitos outros temas, são imprescindíveis tanto conhecimentos éticos, políticos e culturais quanto científicos. Isso por si só já justifica, na educação formal, a presença da área de Ciências da Natureza, e de seu compromisso com a formação integral dos alunos (BRASIL, 2018, p. 321)

Fica sob responsabilidade, também, das Ciências da Natureza propiciar uma compreensão de mundo, por meio de um saber científico. Para isso, é necessário que, desde o Ensino Fundamental, seja promovido o desenvolvimento da alfabetização científica. Chassot (2018, p. 91) contribui com esse pensamento ao dizer que "são o Ensino Médio e Ensino Fundamental o locus para a realização de uma alfabetização científica”. Para Chassot (2018), um professor não pode considerar um ser alfabetizado cientificamente, pela sua capacidade de memorizar conceitos e definições, mas, sim, quando é capaz de fazer uso do saber científico para realizar uma leitura de mundo.

Para a BNCC (BRASIL, 2018, p. 321), a área de Ciências da Natureza precisa estar preocupada não com a reprodução de teorias e memorização de conceitos mas com "o desenvolvimento da capacidade de atuação no e sobre o mundo, importante ao exercício pleno da cidadania como também façam escolhas e intervenções conscientes e pautadas nos princípios da sustentabilidade e do bem comum".

A orientação, para tanto, é agir de forma analítica não limitadas a um conjunto de etapas rígidas e fixas e não restritas apenas à manipulação do objeto de estudo. A proposta da BNCC (BRASIL, 2018), diante do que nos é apresentado é que o planejamento do ensino esteja pautado no protagonismo do estudante. Sendo assim, propõe:

[...] organizar as situações de aprendizagem partindo de questões que sejam desafiadoras e, reconhecendo a diversidade cultural, estimulem o interesse e a curiosidade científica dos alunos e possibilitem definir problemas, levantar, analisar e representar resultados; comunicar conclusões e propor intervenções (BRASIL, 2018, p. 322).

Uma possibilidade para o desenvolvimento dessas habilidades é uma docência em que o professor atue como um propositor de questões-problemas significativas, crie espaço para que haja: levantamento e teste de hipóteses, coleta e registro de dados, comunicação dos achados e estabeleça momentos de interação. Nesse caso, promove-se a capacidade de argumentação (CARVALHO, 2013). 
Pensada dessa forma, a prática docente vai requerer planejamento e desenvolvimento de atividades que contemplem as competências específicas exigidas na área de Ciências da Natureza, já que a BNCC (BRASIL, 2018) destaca a importância da indagação e a aprendizagem de conteúdos que possuam uma relação CTSA.

No componente curricular de Ciências, é possível identificar, já nos Anos Iniciais do Ensino Fundamental, propostas para tratar de questões que estão presentes na relação CTSA, pois, nesse nível escolar, as crianças já possuem "vivências, saberes, interesses e curiosidades sobre o mundo natural e tecnológico que devem ser valorizados e mobilizados" (BRASIL, 2018, p. 331). Nos Anos Finais do Ensino Fundamental, haverá um aprofundamento dos saberes sobre a relação "ciência, a natureza, a tecnologia e a sociedade, o que significa lançar mão do conhecimento científico e tecnológico para compreender os fenômenos e conhecer o mundo, o ambiente, a dinâmica da natureza" (BRASIL, 2018, p. 343).

As questões da relação ciência/sociedade, como as destacadas pela BNCC (BRASIL, 2018), quando trabalhadas, buscam principalmente dar voz aos educandos, para que se posicionem em momentos de discussão (ZEIDLER; NICHOLS, 2009). Esses diálogos, quando são pautados em indagações sobre o saber científico, propicia ao professor um trabalho direcionado à argumentação e ao senso crítico. (BRAGA; MARTINS; CONRADO, 2019; MARTÍNEZ-PÉREZ, 2012).

Para Sasseron (2015, p. 60) "promover interações discursivas contribui diretamente para o desenvolvimento do pensamento e, consequentemente, para o desenvolvimento intelectual". À medida em que incentivadas as discussões avançam e insere-se os alunos de forma processual na cultura científica, pois investigar e argumentar faz parte do fazer científico.

A BNCC (BRASIL, 2018) traz uma gama de possibilidades para um trabalho questionador, em toda a educação básica, por meio da utilização de temas como:

\begin{abstract}
[...] desmatamento, mudanças climáticas, energia nuclear e uso de transgênicos na agricultura - já passaram a incorporar as preocupações de muitos brasileiros. Nesse contexto, a Ciência e a Tecnologia tendem a ser encaradas não somente como ferramentas capazes de solucionar problemas, tanto os dos indivíduos como os da sociedade, mas também como uma abertura para novas visões de mundo (BRASIL, 2018, p. 547).
\end{abstract}

A partir do que preconiza a BNCC (BRASIL, 2018), é evidente o mérito de compreendermos de que forma a aplicação da Ciência e da Tecnologia interfere, e nem sempre de forma positiva, em nossas vidas e no meio ambiente. Por isso, Chassot (2018) diz ser essencial compreendermos as duas versões da Ciência: a primeira é aquela que promove o desenvolvimento e, consequentemente, nos proporciona conforto; a segunda corresponde àquela que é ou pode ser "uma bruxa malvada que programa grãos ou animais que são fontes alimentares da humanidade para se tornarem estéreis numa segunda reprodução" (CHASSOT, 2018, p.115).

Para Martínez-Pérez (2012, p. 60), a discussão de assuntos dessa monta reclama a "formação de cidadãos dotados de conhecimentos e capacidades para avaliar responsavelmente problemas científicos e tecnológicos na sociedade atual". Todavia, essa formação não vem sendo acatada no processo formativo percorrido pelos discentes, durante a Educação Básica; e, em assim sendo, dificilmente poderemos ter esse perfil de cidadãos. A ação dos docentes das Ciências, como tem sido efetivada, fixa, reiteramos, uma distância da realidade e foca no tratamento do saber científico como um produto acabado, numa comprovação errônea de uma Ciência compreendida como neutra (CHASSOT, 2018). 
Aliada a esse contexto, a maneira disciplinar, como está organizado o currículo, pode ser uma das fortes influências para a fragmentação da disciplina fragilizando sua abordagem interativa com outras áreas do saber (MARTÍNEZ-PÉREZ, 2012; HOFFMANN et al., 2013). Para Martínez-Pérez (2012), a relevância da interdisciplinaridade urge uma discussão visando às dimensões éticas, políticas, sociais e religiosas.

Para Ziman (1980), um dos objetivos que podemos alcançar ao trabalharmos conteúdos polêmicos, a partir de uma perspectiva interdisciplinar, é propiciar a compreensão social da Ciência. Sendo assim, a interdisciplinaridade, aliada aos estudos que englobam as controvérsias sociocientíficas, "resulta em um importante componente para evitar o reducionismo técnico das disciplinas, pois os problemas de ordem científica e tecnológica estão relacionados a várias dimensões sociais” (MARTÍNEZ-PÉREZ, 2012, p.15).

Embora a interdisciplinaridade seja dotada de vários significados, convergimos para o que é destacado por Japiassu (1976), ao enfatizar que estamos caminhando para uma proposta interdisciplinar, quando somos capazes de efetivarmos diálogos e parcerias, para que possamos reestabelecer a ligação entre os saberes que ainda são trabalhos de modo fragmentados. A BNCC (BRASIL, 2018) destaca, em suas propostas, a necessidade do planejamento de ensino voltado para a interação entre as disciplinas escolares. Sendo assim, destacamos que a utilização do Ensino de Ciências, pela pesquisa e polemização, pode ser planejado para trabalhar de maneira interdisciplinar.

\section{Metodologia}

Essa pesquisa foi desenvolvida dentro de um enfoque qualitativo, em que a compreensão do fenômeno investigado ocorre de forma descritiva, pois os dados obtidos são por meio de palavras e não de números (BOGDAN; BINKLEN, 1994; MINAYO, 2002; MORAES, 2003). Quanto ao procedimento, se configura como uma pesquisa documental.

Para Pádua (1997, p. 62), “a pesquisa documental é aquela realizada a partir de documentos, contemporâneos ou retrospectivos, considerados cientificamente autênticos (não fraudados)". Por conseguinte, a pesquisa documental se coaduna com o objetivo do nosso estudo, ao buscarmos realizar uma análise da Base Nacional Comum Curricular (BRASIL, 2018). Nossa escolha se dá, logo, no sentido de compreender quais são as habilidades que os discentes precisam desenvolver, durante a Educação Básica, frente a situações que envolvem querelas sociocientífica. Constata-se, à vista disso, que temos um significativo enfoque didático no ensino por investigação.

No exame dos dados, optamos, assim, pela análise do conteúdo, proposta por Bardin (1977). Para empreendermos o estudo, realizamos as seguintes etapas: pré-análise, que inclui a leitura flutuante e a escolha dos documentos que compõem o referencial; seleção das unidades de registro; e, por fim, a categorização necessária para consolidar as análises de forma objetiva. A leitura da BNCC (BRASIL, 2018) foi o momento em que o pesquisador teve o primeiro contato com o documento. Essa leitura conferiu-lhe, de forma gradativa, uma precisão para as etapas da triagem dos dados. Isso porque, a escolha do documento, de acordo com Bardin (1977), já é um momento apriorístico da pesquisa.

Ainda tomando o método de Bardin (1977), como norte para a pesquisa, na segunda etapa denominada de seleção das unidades de registro, foi essencial que, diante da totalidade do material, os recortes recebessem olhares mais perscrutadores, numa espécie de familiarização com todas as minúcias do documento, reportadas à sua realidade. Ao tempo em que a BNCC (BRASIL, 2018) engloba diferentes áreas do saber, busca atender aos objetivos 
de um estudo proposto pela via da pesquisa e requer que os recortes se deem com maior propriedade na área de Ciências da Natureza dos Anos Iniciais do Ensino Fundamental ao Ensino Médio. Para Bardin (1977), esse recorte pode ser no nível semântico (tema) ou linguístico (palavra ou frase); optou-se por um recorte no nível semântico.

Na BNCC (BRASIL, 2018), os conteúdos, conceitos e processos são organizados em unidades temáticas. Assim, na área de Ciências da Natureza, nos Anos Iniciais e Finais do Ensino Fundamental, as unidades analisadas foram: Matéria e Energia; Vida e Evolução; e Terra e Universo. Já no Ensino Médio, analisamos as unidades: Matéria e Energia; Vida; e Terra e Cosmo.

Para proceder com a terceira etapa, a categorização, Bardin (1977, p. 117) esclarece que "categorias são rubricas ou classes, as quais reúnem um grupo de elementos (unidades de registro, no caso da análise de conteúdo) sob um título genérico, agrupamento esse efetuado em razão dos caracteres comuns destes elementos". Para o autor (1977), classificação é semântica, quando as informações podem ser agrupadas de acordo com um mesmo tema. Desta forma, as especificações que emergiram após a leitura da BNCC (BRASIL, 2018) estão relacionadas a uma recorrência nas unidades temáticas, no que se refere às habilidades a serem desenvolvidas, frente a indagações de cunho científico e social.

Desde os Anos Iniciais do Ensino Fundamental ao Ensino Médio, há a enunciação de habilidades que precisam ser desenvolvidas e que estão articuladas a opiniões distintas, no que se refere à disciplina Ciências, na relação com a sociedade. Portanto, foi devido a essa verificação que surgiu a necessidade de se apresentar a primeira categoria: a categoria das habilidades a serem desenvolvidas, articuladas à fundamental ligação sociocientífica. Verificou-se, dessarte, que se apresentam, unanimemente, nas referidas etapas de ensino, em cada uma das unidades do material pesquisado.

O documento (BRASIL, 2018) compreende competência como a capacidade de mobilizar os saberes conceituais, procedimentais e atitudinais para resolver as demandas presentes no cotidiano. Ressaltamos que no Ensino Médio a unidade Vida, Terra e Cosmo é resultado da articulação entre as unidades Vida e Evolução e Terra e Universo presente no Ensino Fundamental.

É importante destacar que alguns dos aportes teóricos utilizados nessa pesquisa, como Martínez-Perez (2012), ressaltam a importância das questões controversas serem trabalhadas de forma interdisciplinar, para que possamos contemplar suas diferentes dimensões. A partir disso é que se buscou verificar quais as outras áreas, além das Ciências da Natureza, têm como fundamento as controvérsias sociocientíficas. Apenas no referencial para o Ensino Médio, na área de Ciências Humanas e Sociais Aplicadas, encontrou-se essa possibilidade. Dessa forma, surgiu a categoria: "temas controversos e a interdisciplinaridade".

Com todas as etapas cumpridas e as categorias de análise já consolidadas, tivemos condições de observar quais respostas os conteúdos conferiam a perguntas da pesquisa e quais lacunas na prática docente poderiam existir, diante da ação docente alicerçada pela BNCC. É importante destacar que nem todos os anos escolares apontam para o desenvolvimento de habilidades articuladas aos assuntos controversos. Por isso, buscamos destacar apenas os anos escolares que contemplam o objetivo dessa pesquisa.

Por meio dos trechos retirados da Base Nacional Comum Curricular (BNCC), apresentamos e discutimos as controvérsias sociocientíficas e as habilidades que precisam ser desenvolvidas. Ressaltamos que na competência 1, para o Ensino Médio, a BNCC (BRASIL, 2018, p.554) destaca que os discentes devem ser capazes de "analisar fenômenos naturais e processos tecnológicos, com base nas interações e relações entre matéria e energia, para 
Revista de Educação, Ciência e Tecnologia

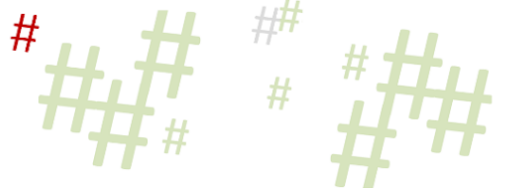

propor ações individuais e coletivas que aperfeiçoem processos produtivos, minimizem impactos socioambientais e melhorem as condições de vida em âmbito local, regional e global".

\section{Resultados e Discussões}

Os resultados da pesquisa estão organizados de acordo com as propostas da BNCC conforme suas unidades temáticas.

\subsection{Matéria e Energia}

Nos Anos Iniciais, na unidade Matéria e energia, a BNCC (BRASIL, 2018) destaca como sendo importante a compreensão da constituição dos materiais que são produzidos e sua relação com o meio ambiente. Essa necessidade parte do pressuposto de que o consumo excessivo e o descarte inadequado desses materiais podem causar danos ao meio ambiente e como o homem - parte integrante da biosfera - é diretamente afetado. Essas questões sociais podem promover discussões baseadas na busca de respostas para a pergunta: como podemos consumir, de forma sustentável, sem causar danos ao meio ambiente?

Quadro 1 - Propostas da BNCC na unidade temática Matéria e Energia

\begin{tabular}{|c|c|}
\hline Anos Iniciais & Categoria \\
\hline & Habilidades a serem desenvolvidas articuladas a controvérsias sociocientíficas \\
\hline $1^{\mathrm{a}}$ ano & $\begin{array}{l}\text { Comparar características de diferentes materiais presentes em objetos de uso cotidiano, } \\
\text { discutindo sua origem, os modos como são descartados e como podem ser usados de } \\
\text { forma mais consciente" (BRASIL, 2018, p. 332) }\end{array}$ \\
\hline $5^{\mathrm{a}}$ ano & $\begin{array}{l}\text { Identificar os principais usos da água e de outros materiais nas atividades cotidianas para } \\
\text { discutir e propor formas sustentáveis de utilização desses recursos. Assim como construir } \\
\text { propostas coletivas para um consumo mais consciente e criar soluções tecnológicas para o } \\
\text { descarte adequado e a reutilização ou reciclagem de materiais consumidos na escola e/ou } \\
\text { na vida cotidiana (BRASIL, 2018, p. 341). }\end{array}$ \\
\hline Anos Finais & Habilidades a serem desenvolvidas articuladas a controvérsias sociocientíficas \\
\hline $6^{\mathrm{a}}$ ano & $\begin{array}{l}\text { Associar a produção de medicamentos e outros materiais sintéticos ao desenvolvimento } \\
\text { científico e tecnológico, reconhecendo benefícios e avaliando impactos socioambientais } \\
\text { (BRASIL, 2018, p.345). }\end{array}$ \\
\hline $7^{\mathrm{a}}$ ano & $\begin{array}{l}\text { Discutir o uso de diferentes tipos de combustível e máquinas térmicas ao longo do tempo, } \\
\text { para avaliar avanços, questões econômicas e problemas socioambientais causados pela } \\
\text { produção e uso desses materiais e máquinas. (BRASIL, 2018, p. 347). }\end{array}$ \\
\hline $8^{\mathrm{a}}$ ano & $\begin{array}{l}\text { Propor ações coletivas para otimizar o uso de energia elétrica em sua escola e/ou } \\
\text { comunidade, com base na seleção de equipamentos segundo critérios de sustentabilidade } \\
\text { (consumo de energia e eficiência energética) e hábitos de consumo responsável. Discutir e } \\
\text { avaliar usinas de geração de energia elétrica (termelétricas, hidrelétricas, eólicas etc.), suas } \\
\text { semelhanças e diferenças, seus impactos socioambientais, e como essa energia chega e é } \\
\text { usada em sua cidade, comunidade, casa ou escola (BRASIL, 2018, p. 349). }\end{array}$ \\
\hline Ensino Médio & Habilidades a serem desenvolvidas e articuladas a controvérsias sociocientíficas \\
\hline $\begin{array}{l}\text { Competência } \\
\text { específica } 1\end{array}$ & $\begin{array}{l}\text { Analisar e representar, com ou sem o uso de dispositivos e de aplicativos digitais } \\
\text { específicos, as transformações e conservações em sistemas que envolvam quantidade de } \\
\text { matéria, de energia e de movimento para realizar previsões sobre seus comportamentos em } \\
\text { situações cotidianas e em processos produtivos que priorizem o desenvolvimento } \\
\text { sustentável, o uso consciente dos recursos naturais e a preservação da vida em todas as } \\
\text { suas formas. Utilizar o conhecimento sobre as radiações e suas origens para avaliar as } \\
\text { potencialidades e os riscos de sua aplicação em equipamentos de uso cotidiano, na saúde, } \\
\text { no ambiente, na indústria, na agricultura e na geração de energia elétrica. Avaliar os }\end{array}$ \\
\hline
\end{tabular}


benefícios e os riscos à saúde e ao ambiente, considerando a composição, a toxicidade e a reatividade de diferentes materiais e produtos, como também o nível de exposição a eles, posicionando-se criticamente e propondo soluções individuais e/ou coletivas para seus usos e descartes responsáveis.

\section{Fonte: elaborado pelos autores}

Para Martínez-Pérez (2012), a resolução desses problemas sociocientíficos não se resumem a uma resposta certa ou errada, pois exige uma articulação entre várias dimensões, sendo necessária uma compreensão interdisciplinar. Embora possa parecer que essas discussões estejam além da capacidade de compreensão dos educandos dos Anos Iniciais, o que se espera é que essas questões sejam resolvidas por meio de reflexões e tomadas de decisão (POZO; CRESPO, 2019).

Nos Anos Finais do Ensino Fundamental é ressaltada a importância das controvérsias sociocientíficas, para conduzir a compreensão da ambiguidade na qual a Ciência está inserida: busca atender as necessidades da humanidade, entretanto acaba gerando impactos na sociedade e no meio ambiente. Martínez-Pérez (2012), Chassot (2018) e Reis (2006) destacam a relevância das questões controversas para a percepção de que não existe neutralidade na Ciência.

Para a competência 1 no Ensino Médio, a BNCC (BRASIL, 2018) salienta que os discentes, além de proporem ações - de maneira individual e coletiva, que culminem na resolução ou minimização dos problemas socioambientais, tomem decisões responsáveis e conscientes. Dessa forma, ressaltamos a importância das discussões de assuntos controversos, buscando promover o desenvolvimento de habilidades essenciais para o exercício da cidadania (HILÁRIO; REIS, 2011).

\subsection{Vida e Evolução}

Da forma como está apresentada na BNCC (BRASIL, 2018), a unidade Vida e Evolução nos Anos Iniciais não traz, de maneira explícita, conteúdos que possam ser trabalhados, a partir da perspectiva da controvérsia sociocientífica. Destacamos que na competência específica 2 para o Ensino Médio, a BNCC (BRASIL, 2018, p. 556) argumenta que os alunos deverão "analisar e utilizar interpretações sobre a dinâmica da Vida, da Terra e do Cosmos para elaborar argumentos, realizar previsões sobre o funcionamento e a Evolução dos Seres Vivos e do Universo, e fundamentar e defender decisões éticas e responsáveis". As habilidades a serem desenvolvidas nessa competência estão presentes no quadro 2 .

Quadro 2 - Propostas da BNCC na unidade temática Vida e Evolução

\begin{tabular}{|c|c|}
\hline Anos Finais & Categoria \\
\hline \multirow[b]{2}{*}{$7^{\mathrm{a}}$ ano } & Habilidades a serem desenvolvidas e articuladas a controvérsias sociocientíficas \\
\hline & $\begin{array}{l}\text { Avaliar como os impactos provocados por catástrofes naturais ou mudanças nos } \\
\text { componentes físicos, biológicos ou sociais de um ecossistema afetam suas populações, } \\
\text { podendo ameaçar ou provocar a extinção de espécies, alteração de hábitos, migração etc. } \\
\text { Argumentar sobre a importância da vacinação para a saúde pública, com base em } \\
\text { informações sobre a maneira como a vacina atua no organismo e o papel histórico da } \\
\text { vacinação para a manutenção da saúde individual e coletiva e para a erradicação de } \\
\text { doenças. Analisar historicamente o uso da tecnologia, incluindo a digital, nas diferentes } \\
\text { dimensões da vida humana, considerando indicadores ambientais e de qualidade de vida } \\
\text { (BRASIL, 2018, p.347). }\end{array}$ \\
\hline \multirow[t]{2}{*}{$8^{\mathrm{a}}$ ano } & $\begin{array}{l}\text { Comparar o modo de ação e a eficácia dos diversos métodos contraceptivos e justificar a } \\
\text { necessidade de compartilhar a responsabilidade na escolha e na utilização do método mais } \\
\text { adequado à prevenção da gravidez precoce e indesejada e de Doenças Sexualmente } \\
\text { Transmissíveis (DST) (BRASIL, 2018, p. 349). }\end{array}$ \\
\hline & Propor iniciativas individuais e coletivas para a solução de problemas ambientais da \\
\hline
\end{tabular}


Revista de Educação, Ciência e Tecnologia

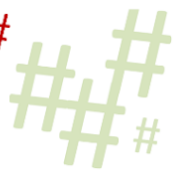

\begin{tabular}{|c|c|}
\hline $9^{\text {a }}$ ano & $\begin{array}{l}\text { cidade ou da comunidade, com base na análise de ações de consumo consciente e de } \\
\text { sustentabilidade bem-sucedidas (BRASIL, 2018, p. 350). }\end{array}$ \\
\hline $\begin{array}{c}\text { Ensino Médio } \\
\text { (Vida, Terra e } \\
\text { Cosmos) }\end{array}$ & Habilidades a serem desenvolvidas e articuladas a controvérsias sociocientíficas \\
\hline $\begin{array}{l}\text { Competência } \\
\text { específica } 2\end{array}$ & $\begin{array}{l}\text { Analisar e discutir modelos, teorias e leis propostos em diferentes épocas e culturas para } \\
\text { comparar distintas explicações sobre o surgimento e a evolução da Vida, da Terra e do } \\
\text { Universo com as teorias científicas aceitas atualmente. Avaliar e prever efeitos de } \\
\text { intervenções nos ecossistemas, e seus impactos nos seres vivos e no corpo humano, com } \\
\text { base nos mecanismos de manutenção da vida, nos ciclos da matéria e nas transformações e } \\
\text { transferências de energia. Discutir a importância da preservação e conservação da } \\
\text { biodiversidade, considerando parâmetros qualitativos e quantitativos, e avaliar os efeitos } \\
\text { da ação humana e das políticas ambientais para a garantia da sustentabilidade do planeta. } \\
\text { Aplicar os princípios da evolução biológica para analisar a história humana, considerando } \\
\text { sua origem, diversificação, dispersão pelo planeta e diferentes formas de interação com a } \\
\text { natureza, valorizando e respeitando a diversidade étnica e cultural humana. Analisar a } \\
\text { evolução estelar associando-a aos modelos de origem e distribuição dos elementos } \\
\text { químicos no Universo, compreendendo suas relações com as condições necessárias ao } \\
\text { surgimento de sistemas solares e planetários, suas estruturas e composições e as } \\
\text { possibilidades de existência de vida (BRASIL, 2018, p. 557). }\end{array}$ \\
\hline
\end{tabular}

Fonte: elaborado pelos autores

Para os Anos Iniciais, a BNCC (BRASIL, 2018) evidencia que a unidade Vida e Evolução trabalhe apenas com questões relacionadas às características dos seres vivos e o desenvolvimento da compreensão sobre os animais ao nosso redor. Contudo, sabemos que essa unidade é capaz de abordar tópicos polêmicos e que podem ser discutidos, a partir de diferentes perspectivas, sendo este um dos objetivos ao inserirmos controvérsias sociocientíficas nas aulas (REIS, 2006; KRUPCZAK; AIRES, 2019).

Já nos Anos Finais do Ensino Fundamental, exceto no sexto ano, a BNCC (BRASIL, 2018) ressalta a importância de compreender o homem como parte integrante da natureza, capaz de modificá-la, interferindo em processos naturais provocando um desequilíbrio ambiental. Ainda ressalta que os educandos precisam assumir o protagonismo, para realizar escolhas e se posicionar diante de questões socioambientais.

Martínez-Pérez (2012, p. 60) contribui com esse contexto ao dizer que "as controvérsias envolvidas nas discussões públicas sobre QSC exigem a formação de cidadãos dotados de conhecimentos e capacidades para avaliar responsavelmente problemas científicos e tecnológicos na sociedade atual". Para isso, é preciso, além de abordar as controvérsias sociocientíficas, fazer uso de diferentes proposições, no trabalho com a disciplina.

Destacamos, ainda, a proposta de Carvalho (2013), como uma visão metodológica que se aproxima das propostas da BNCC (BRASIL, 2018). Ou seja, para essa autora, as Ciências da Natureza não se resumem à reprodução de teorias, memorização de conceitos e outras formas de ampliar a imagem distorcida das Ciências (GIL-PÉREZ et al., 2001), mas à busca de debates sobre os conteúdos, sendo a pesquisa uma condição necessária para o desenvolvimento de habilidades.

As habilidades que precisam ser desenvolvidas na competência 2 no Ensino Médio dizem respeito à compreensão da Evolução dos Seres Vivos, surgimento da vida e impactos ambientais causados pelas ações antrópicas. Evolução e surgimento da vida são controvérsias sociocientíficas tão marcantes, quanto os impactos ambientais causados pela relação CTS.

Nesses assuntos significativos, que dividem opiniões e são defendidos sob dessemelhantes teorizações, é importante que os professores esclareçam que é essencial o respeito, pois como destacado por Krupczake Aires (2019, p. 279), "a visão de mundo de uma 
pessoa é resultado das suas experiências e vivências particulares". Nesse sentido, aprendizagem de conteúdos atitudinais também precisam levadas em consideração.

Ainda em relação à competência 2, de acordo com a BNCC (2018, p.556), para o desenvolvimento das habilidades, é necessário saber "elaborar argumentos, realizar previsões sobre o funcionamento e a Evolução dos Seres Vivos e do Universo, e fundamentar e defender decisões éticas e responsáveis".

Para Sasseron (2015, p. 60), o desenvolvimento da argumentação para que possa contribuir com a apropriação da linguagem científica não se deve limitar a colocar opiniões pessoais em conflitos, porque "a avaliação de problemas, os processos engendrados para sua resolução e a comunicação de ideias resultam em um trabalho argumentativo de envolvimento com a linguagem científica". A autora ainda destaca que o ensino por observação da realidade, aliado à argumentação, contribui para o rompimento de práticas didáticas descontextualizada, melhor dizendo, com a maneira como cada Ciência constrói seus saberes.

\subsection{Terra e Universo}

Para os Anos Iniciais a BNCC (BRASIL, 2018) não apresenta questões controversas nessa unidade. As orientações para esse nível escolar estão voltadas para despertar a curiosidade sobre os objetos celestes. No sexto ano, que marca o início dos Anos Finais, também não há propostas para trabalhar as controvérsias sociocientíficas. A competência específica 3, para o Ensino Médio destaca a necessidade de os discentes serem capazes de investigar e avaliar a aplicação e a implicação da Ciência e da Tecnologia no mundo.

Quadro 3 - Propostas da BNCC na unidade temática Terra e Universo

\begin{tabular}{|c|c|}
\hline Anos Finais & Categoria \\
\hline & Habilidades a serem desenvolvidas e articuladas a controvérsias sociocientíficas \\
\hline $7^{\mathrm{a}}$ ano & $\begin{array}{l}\text { Descrever o mecanismo natural do efeito estufa, seu papel fundamental para o } \\
\text { desenvolvimento da vida na Terra, discutir as ações humanas responsáveis pelo seu } \\
\text { aumento artificial (queima dos combustíveis fósseis, desmatamento, queimadas etc.) e } \\
\text { selecionar e implementar propostas para a reversão ou controle desse quadro. Justificar a } \\
\text { importância da camada de ozônio para a vida na Terra, identificando os fatores que } \\
\text { aumentam ou diminuem sua presença na atmosfera, e discutir propostas individuais e } \\
\text { coletivas para sua preservação (BRASIL, } 2018, \text { p. } 347 \text { ). }\end{array}$ \\
\hline $8^{\mathrm{a}}$ ano & $\begin{array}{l}\text { Discutir iniciativas que contribuam para restabelecer o equilíbrio ambiental a partir da } \\
\text { identificação de alterações climáticas regionais e globais provocadas pela intervenção } \\
\text { humana (BRASIL, 2018, p. 349). }\end{array}$ \\
\hline $9^{\mathrm{a}}$ ano & $\begin{array}{l}\text { Selecionar argumentos sobre a viabilidade da sobrevivência humana fora da Terra, com } \\
\text { base nas condições necessárias à vida, nas características dos planetas e nas distâncias e } \\
\text { nos tempos envolvidos em viagens interplanetárias e interestelares (BRASIL, 2018, p. } \\
351 \text { ). }\end{array}$ \\
\hline $\begin{array}{l}\text { Ensino Médio } \\
\text { (Vida, Terra e } \\
\text { Cosmos) }\end{array}$ & Habilidades a serem desenvolvidas e articuladas a controvérsias sociocientíficas \\
\hline $\begin{array}{c}\text { Competência } \\
\text { específica } 3\end{array}$ & $\begin{array}{l}\text { Avaliar os riscos envolvidos em atividades cotidianas, aplicando conhecimentos das } \\
\text { Ciências da Natureza, para justificar o uso de equipamentos e recursos, bem como } \\
\text { comportamentos de segurança, visando à integridade física, individual e coletiva, e } \\
\text { socioambiental, podendo fazer uso de dispositivos e aplicativos digitais que viabilizem a } \\
\text { estruturação de simulações de tais riscos. Analisar as propriedades dos materiais para } \\
\text { avaliar a adequação de seu uso em diferentes aplicações (industriais, cotidianas, } \\
\text { arquitetônicas ou tecnológicas) e/ ou propor soluções seguras e sustentáveis considerando } \\
\text { seu contexto local e cotidiano. Investigar e analisar o funcionamento de equipamentos } \\
\text { elétricos e/ou eletrônicos e sistemas de automação para compreender as tecnologias } \\
\text { contemporâneas e avaliar seus impactos sociais, culturais e ambientais. Analisar questões }\end{array}$ \\
\hline
\end{tabular}


socioambientais, políticas e econômicas relativas à dependência do mundo atual em relação aos recursos não renováveis e discutir a necessidade de introdução de alternativas e novas tecnologias energéticas e de materiais, comparando diferentes tipos de motores e processos de produção de novos materiais (BRASIL, 2018, p.559-560).

Fonte: elaborado pelos autores

Nos Anos Finais do Ensino Fundamental a BNCC (BRASIL, 2018) ressalta a importância da discussão sobre os fatores envolvidos na mudança do clima no planeta, a partir da interferência humana. Ao que acrescenta quais ações precisam ser desenvolvidas para que possamos reverter esse desequilíbrio. Essas questões sociocientíficas estão veiculadas em diferentes meios de comunicação e estão próximas do cotidiano (MARTÍNEZ-PÉREZ, 2012; FONSECA, 2017).

Assim, ao propormos discussões sobre esses tópicos, buscamos a formação de cidadãos que possuam um conjunto de saberes, que os possibilite avaliar de forma responsável as informações que envolvem problemas de ordem científico e tecnológico, fornecidas pelos veículos de comunicação (MARTÍNEZ-PÉREZ, 2012). A BNCC (BRASIL, 2018) ainda reforça que, nos Anos Finais se objetiva desenvolver a compreensão de mundo, de forma sistêmica, e como o desequilíbrio das partes afeta o todo.

Na unidade Vida, Terra e Cosmo, a BNCC (BRASIL, 2018) salienta a necessidade de serem trabalhados assuntos que promovam discussões sobre a origem e Evolução da vida. Em uma pesquisa realizada por Martínez-Pérez (2012) é destacada a maneira como a crença de um professor pode influenciar no tratamento de questões conflitantes, como estas. Para o autor, mesmo que tais conteúdos sejam complexos, "abordá-los em sala de aula é significativo para trabalhar com os estudantes aspectos éticos e morais que passam despercebidos no Ensino de Ciências tradicional” (MARTÍNEZ-PÉREZ, 2012, p. 225-226).

Para isso, de acordo com a BNCC (BRASIL, 2018), é necessário que os professores de Ciências da Natureza estejam dispostos a superar um ensino que se resume "a simples exemplificação de conceitos com fatos ou situações cotidianas". Recomenda-se buscar o protagonismo dos alunos no enfrentamento de questões sobre "consumo, energia, segurança, ambiente, saúde, entre outras" (BRASIL, 2018, p. 549). Nesse sentido, buscamos destacar o ensino inquiridor onde os educandos diminuem a passividade em que se encontram na maioria das vezes e passam a estar envolvidos durante as atividades, desenvolvendo a argumentação, levantando hipóteses etc.

\subsection{Temas controversos e a interdisciplinaridade}

Como poderemos analisar no quadro 4, na área de Ciências Humanas e Sociais Aplicadas, existem habilidades articuladas a controvérsias sociocientíficas que podem ser desenvolvidas ao serem trabalhadas em conjunto com professores da área de Ciências da Natureza, tais como o meio ambiente e os impactos da Ciência e Tecnologia. Para isso, a BNCC (BRASIL, 2018) orienta que os currículos escolares busquem decidir de que maneira os componentes curriculares poderão ser organizados de forma interdisciplinar e quais as metodologias que podem ser utilizadas, para contribuir com a efetivação da interdisciplinaridade no cotidiano escolar.

No quadro 4 apresentamos as competências específicas 1, 2 e 3 que constituem a área de Ciências Humanas e Sociais Aplicadas. Na competência 1, a BNCC (BRASIL, 2018) esclarece que os discentes deverão ser capazes de analisar processos políticos, econômicos, sociais, ambientais e culturais, de modo que, através da sua compreensão, possam utilizar o saber científico, para se posicionar de forma crítica frente a esses processos. 
Na competência 2, é necessário saber "Analisar a formação de territórios e fronteiras em diferentes tempos e espaços, mediante a compreensão das relações de poder que determinam as territorialidades e o papel geopolítico dos Estados-nações" (BRASIL, 2018, p. 573). Já na competência 3, é salientada a capacidade de analisar e avaliar de que forma se dá a relação entre os diferentes grupos, povos e sociedade com a natureza e seus impactos econômicos e socioambientais.

Quadro 4 - Propostas da BNCC na área de ciências humanas e sociais aplicadas

\begin{tabular}{|c|c|}
\hline $\begin{array}{l}\text { Área do conhecimento } \\
\text { Ciências Humanas e Sociais } \\
\text { Aplicadas }\end{array}$ & Categoria \\
\hline Competência específica 1 & $\begin{array}{l}\text { Habilidades a serem desenvolvidas e articuladas a controvérsias } \\
\text { sociocientíficas }\end{array}$ \\
\hline & $\begin{array}{l}\text { Identificar, analisar e comparar diferentes fontes e narrativas expressas em } \\
\text { diversas linguagens, com vistas à compreensão de ideias filosóficas e de } \\
\text { processos e eventos históricos, geográficos, políticos, econômicos, sociais, } \\
\text { ambientais e culturais. Elaborar hipóteses, selecionar evidências e compor } \\
\text { argumentos relativos a processos políticos, econômicos, sociais, ambientais, } \\
\text { culturais e epistemológicos, com base na sistematização de dados e } \\
\text { informações de diversas naturezas (BRASIL, 2018, p. 572). }\end{array}$ \\
\hline Competência específica 2 & $\begin{array}{l}\text { Habilidades a serem desenvolvidas e articuladas a controvérsias } \\
\text { sociocientíficas }\end{array}$ \\
\hline & $\begin{array}{l}\text { Analisar e avaliar os impactos das tecnologias na estruturação e nas dinâmicas } \\
\text { de grupos, povos e sociedades contemporâneos (fluxos populacionais, } \\
\text { financeiros, de mercadorias, de informações, de valores éticos e culturais etc.), } \\
\text { bem como suas interferências nas decisões políticas, sociais, ambientais, } \\
\text { econômicas e culturais (BRASIL,2018, p. 573) }\end{array}$ \\
\hline Competência específica 3 & $\begin{array}{l}\text { Habilidades a serem desenvolvidas e articuladas a controvérsias } \\
\text { sociocientíficas }\end{array}$ \\
\hline & $\begin{array}{l}\text { Problematizar hábitos e práticas individuais e coletivos de produção, } \\
\text { reaproveitamento e descarte de resíduos em metrópoles, áreas urbanas e } \\
\text { rurais, e comunidades com diferentes características socioeconômicas, e } \\
\text { elaborar e/ou selecionar propostas de ação que promovam a sustentabilidade } \\
\text { socioambiental, o combate à poluição sistêmica e o consumo responsável. } \\
\text { Analisar e avaliar criticamente os impactos econômicos e socioambientais de } \\
\text { cadeias produtivas ligadas à exploração de recursos naturais e às atividades } \\
\text { agropecuárias em diferentes ambientes e escalas de análise, considerando o } \\
\text { modo de vida das populações locais - entre elas as indígenas, quilombolas e } \\
\text { demais comunidades tradicionais -, suas práticas agroextrativistas e o } \\
\text { compromisso com a sustentabilidade. Debater e avaliar o papel da indústria } \\
\text { cultural e das culturas de massa no estímulo ao consumismo, seus impactos } \\
\text { econômicos e socioambientais, com vistas à percepção crítica das } \\
\text { necessidades criadas pelo consumo e à adoção de hábitos sustentáveis. } \\
\text { Analisar os impactos socioambientais decorrentes de práticas de instituições } \\
\text { governamentais, de empresas e de indivíduos, discutindo as origens dessas } \\
\text { práticas, selecionando, incorporando e promovendo aquelas que favoreçam a } \\
\text { consciência e a ética socioambiental e o consumo responsável. Analisar e } \\
\text { discutir o papel e as competências legais dos organismos nacionais e } \\
\text { internacionais de regulação, controle e fiscalização ambiental e dos acordos } \\
\text { internacionais para a promoção e a garantia de práticas ambientais } \\
\text { sustentáveis. Contextualizar, comparar e avaliar os impactos de diferentes } \\
\text { modelos socioeconômicos no uso dos recursos naturais e na promoção da } \\
\text { sustentabilidade econômica e socioambiental do planeta (como a adoção dos } \\
\text { sistemas da agrobiodiversidade e agroflorestal por diferentes comunidades, } \\
\text { entre outros) (BRASIL, 2018, p. 575). }\end{array}$ \\
\hline
\end{tabular}

Fonte: elaborado pelos autores 
A BNCC (BRASIL, 2018), na área de Ciências Humanas e Sociais Aplicada, envolve filosofia, geografia, história e sociologia, buscando potencializar a capacidade de os discentes articularem os saberes entre diversas áreas. A competência 1, 2 e 3 preza pela capacidade de realizar análises de processos políticos, econômicos, sociais e ambientais. Ainda para a BNCC (BRASIL, 2018) as habilidades presentes nas competências 1, 2 e 3 podem ser desenvolvidas em situações em que se problematiza o ensino e exige a elaboração de hipóteses e o desenvolvimento de argumentos. Nesse contexto, o ensino como pesquisa passa a assumir particular relevância (CARVALHO, 2013; SASSERON, 2015).

A reflexão realizada por Levinson (2001) contribui para a discussão, até aqui estabelecida, sobre a interdisciplinaridade, para tratar de assuntos cruciais para a Ciência. $\mathrm{O}$ autor (2001) levanta o seguinte questionamento: "Quem deve ensinar as controvérsias em Ciências? As Ciências ou as Humanidades?" Levinson (2001) chega à conclusão de que ambas podem apresentar lacunas, por não conseguirem atender a todas as questões sociais, em suas diferentes dimensões e sugere a colaboração entre os professores para que, de forma interdisciplinar, as controvérsias sociocientíficas possam ser postas em prática a partir de diferentes perspectivas.

A pesquisa realizada por Hoffmann et al. (2013, p.1114) mostra que as dificuldades para trabalhar esse tema, de forma interdisciplinar são: "dificuldades de articular diferentes áreas do conhecimento, especificidade de cada disciplina e a resistência à mudança. Esse cenário nos faz refletir sobre a importância de repensarmos como está constituída a formação inicial e continuada dos professores".

\section{Considerações Finais}

A partir da análise das unidades temáticas propostas pela Base Nacional Comum Curricular (BNCC), podemos verificar, ao longo da educação básica, a presença de tópicos controversos na área de Ensino das Ciências da Natureza e as habilidades que precisam ser desenvolvidas. Trazer esses conteúdos para as aulas de Ciências pode contribuir para a compreensão da aplicabilidade dos impactos da Ciência e da Tecnologia na sociedade e no meio ambiente. Acrescendo, também, a desconstrução da imagem distorcida que ainda se tem da Ciência.

As controvérsias sociocientíficas, ao serem trabalhadas, podem contribuir para contextualizar os conteúdos e despertar o interesse dos discentes, já que passam a ser discutidos mais próximos da sua realidade. A promoção da aprendizagem, por meio de debates sobre os diferentes posicionamentos, está ligada ao desenvolvimento de habilidades que são consideradas importantes, para uma atuação efetiva do cidadão, na sociedade, na medida em que se torna capaz de argumentar, de posicionar-se com embasamento científico, fazer escolhas e tomar decisões. Um conjunto de características que revela um cidadão que passou pelo processo de desenvolvimento da Alfabetização Científica.

Sendo as controvérsias sociocientíficas assunto polêmico que envolve a relação CTSA, podem exigir do professor uma compreensão interdisciplinar de diferentes dimensões. A formação do professor será, portanto, decisiva no seu desempenho, ao lidar com a inserção desses tópicos nas aulas. Por isso, enfatizamos a importância da integração de diferentes áreas do saber, para atender o que propõe a BNCC. Assim, cabe potencializarmos as reflexões sobre a formação inicial e continuada desses profissionais. 
O contexto de formação docente também estabelece relação com as habilidades que precisam ser desenvolvidas, de acordo com as novas demandas de aprendizagem propostas pela BNCC, pois o ensino pautado na memorização e reprodução de teorias dificilmente atenderá às suas orientações, no sentido de propiciar situações de aprendizagem que envolvam a resolução de tópicos interpelativos, levantamento e teste de hipóteses. Logo, é necessário que a estratégia didática utilizada pelo professor esteja alinhada com o que se espera que os alunos aprendam.

Assim, o ensino por averiguação pode contribuir com o desenvolvimento de habilidades que estão articuladas aos assuntos discordantes, uma vez que as atividades que são planejadas e executadas na SEI buscam se aproximar do fazer científico. O professor poderá dispor de uma abordagem didática que preza pelo levantamento de hipóteses, protagonismo, comunicação de seus achados, construção de argumentos e defesa de ideias.

Por conseguinte, por meio dessa pesquisa, foi possível analisar que a Base Nacional Comum Curricular aborda as questões controversas e as habilidades que se espera que os educandos desenvolvam. Nosso desafio, com essa reflexão, é contribuir com a prática docente, no desenvolvimento de atividades que auxiliem o processo de ensino e de aprendizagem desses conteúdos. Essa perspectiva de ensino por indagação sobre o entendimento da Ciência, na atualidade, além de contribuir com o desenvolvimento das habilidades articuladas às questões controversas, pode inserir os estudantes em uma nova cultura - a cultura científica -, com vistas a contribuir para transformações de entendimento, hábitos e atitudes sociais.

\section{Referências}

ANGOTTI, J. A. P.; AUTH, M. A. Ciência e tecnologia: implicações sociais e o papel da educação. Ciência \& Educação, Bauru, SP, v. 7, n. 1, p. 15-27, 2001.

BARDIN, L. Análise de conteúdo. Lisboa: Edições 70, 1977.

BAZZO, W. A. A pertinência de abordagens CTS na Educação Tecnológica. Revista Iberoamericana de Educación, Madrid, v. 1, n.28, p. 83-100, 2002.

BOGDAN, Robert; BIKLEN, Sari. Investigação qualitativa em educação: uma introdução à teoria e aos métodos. Portugal: Porto Editora, 1994. p. 134-301.

BRAGA, S.S.; MARTINS, L.; CONRADO, D. M. A argumentação a partir de questões sociocientífica na formação de professores de Biologia. Investigação em ensino de Ciências, v. 24, n.2. p. 120-136, 2019.

BRASIL. Base Nacional Comum Curricular: Educação Infantil e Ensino Fundamental. Brasília: MEC/Secretaria de Educação Básica, 2018.

BRASIL. Base Nacional Comum Curricular: Ensino Médio. Brasília: Ministério da Educação, Secretaria de Educação Básica, 2018.

CACHAPUZ, A., GIL-PÉREZ, D., CARVALHO, A. M. P., PRAIA, J.; VILCHES, A. (Orgs). A necessária Renovação do Ensino de Ciências, São Paulo: Cortez, 2005.

CAMPOS, M. C. C.; NIGRO, R. G. Didática de Ciências: o Ensino-Aprendizagem como Investigação. São Paulo: FTD, 1999. 
CARVALHO, A. M. P. Ensino de ciências por investigação: condições para implementação em sala de aula. São Paulo: Cengage Learning, 2013.

CARVALHO, A. M. P. Ensino e aprendizagem de ciências: referenciais teóricos e dados empíricos da s sequências de ensino investigativo (SEI). In: LONGHINI, M. D. (Org.). O uno e o diverso na educação. Uberlândia, MG: Edufu, 2011. p. 253-266.

CARVALHO, A. M. P.; GIL-PÉREZ, D. Formação de Professores de Ciências: tendências e inovações. 10. ed. São Paulo: Cortez, 2011.

CHASSOT, Attico. Alfabetização Científica: questões e desafios para a educação. Ijuí: Unijuí, 2018.

DELIZOICOV, D.; ANGOTTI, J. A. P.; PERNAMBUCO, M. M. C. Ensino de Ciências: Fundamentos e Métodos. 4. ed. São Paulo: Cortez, 2018.

DUSO, L. Discussões de controvérsias sociocientífica e projetos integrados: perspectivas para o ensino de Ciências. XI Encontro Nacional de Pesquisa em Educação em Ciências. Anais... Florianópolis, SC, Brasil, 2017.

FONSECA, C. V. Representações sociais do aquecimento global: contribuições para aulas de química na educação básica. \#Tear: Revista de Educação, Ciência e Tecnologia, v. 6, n, 2, p. 1-17, 2017. Disponível em: https://periodicos.ifrs.edu.br/index.php/tear/article/view/2399. Acesso em: 29 mar. 2020.

GALVÃO, Cecília; REIS, Pedro; FREIRE, Sofia. A discussão de controvérsias sociocientíficas na formação de professores. Ciênc. educ. (Bauru), Bauru, v. 17, n. 3, p. 505522, 2011. Disponível em:

http://www.scielo.br/scielo.php?script=sci_arttext\&pid=S15167332011000300001\&lng=en\& nrm=iso. Acesso em: 29 mar. 2020.

GIL-PÉREZ, D.; MONTORO, I. F.; ALÍS, J. C.; CACHAPUZ, A.; PRAIA, J. Por uma imagem não deformada do trabalho científico. Ciência \& Educação, Bauru, v.7, n.2, p.125$153,2001$.

HILÁRIO, T.; REIS, P. R. Potencialidades e limitações da discussão de controvérsias sociocientíficas através da representação de papéis: um estudo de caso. Nuances: Estudos sobre Educação, ano XVII, vol.19, n.20, p.86-95, 2011.

HOFFMANN, M. B.; DUSO, L.; SILVÉRIO. L. E. R.; REGINA, S. M. Controvérsias sociocientíficas: limites e possibilidades de uma atividade interdisciplinar na formação continuada de professores de Ciências. IX Congresso Internacional sobre investigación en didáctica de las Ciencias. Anais... Girona, Espanha, p.1111-1115, 2013.

JAPIASSU, H. Interdisciplinaridade e patologia do saber. Rio de Janeiro: Imago, 1976.

KRUPCZAK, C.; AIRES, J. A. Controvérsias sociocientíficas: uma análise da produção acadêmica brasileira.Vidya, v.39, n.1, p. 227-290, 2019.

LEVINSON, R. As ciências ou as humanidades: quem deve ensinar as controvérsias em ciência? Pró-posições, Campinas, v. 12, n. 1 (34), p. 62-72, 2001. 
LICKONA, T. Educating for character. How our schools can teach respect and responsibility, New York: Batam Books, 1991.

MARTINEZ-PEREZ, L. F. Questões sociocientíficas na prática docente: ideologia, autonomia e formação de professores. São Paulo: Editora UNESP, 2012.

MINAYO, M. C. Pesquisa social: teoria, método e criatividade. Rio de Janeiro: Vozes, 2002.

MORAES, R. Uma tempestade de luz: a compreensão possibilitada pela análise textual discursiva. Ciência \& Educação, n. 9 v.2, p. 191-211, 2003.

PÁDUA, E. M. M. Metodologia da pesquisa: abordagem teórico-prática. 2. ed. São Paulo: Papirus, 1997.

PIAGET, J. A epistemologia genética e a pesquisa psicológica. Rio de Janeiro: Freitas Bastos, 1974.

POZO, J. I.; CRESPO, M. A. G. A aprendizagem e o ensino de Ciências: do conhecimento científico ao conhecimento cotidiano. 5. ed. Porto Alegre: Artmed, 2009.

REIS, P. A discussão de assuntos controversos no ensino das ciências. Inovação, Lisboa, n. 12, p. 107-112, 1999.

REIS, P. Uma iniciativa de desenvolvimento profissional para a discussão de controvérsias sociocientíficas em sala de aula. Interacciones, n. 4, p. 64-107, 2006.

SASSERON, Lúcia Helena. Alfabetização científica, ensino por investigação e argumentação: relações entre ciências da natureza e escola. Ensaio Pesquisa em Educação em Ciências, n.17, p. 49-67, 2015.

SCARPA, DANIELA LOPES; CAMPOS, NATÁLIA FERREIRA. Potencialidades do ensino de Biologia por Investigação. Estudos Avançados, São Paulo, v. 32, n. 94, p. 25-41, Dez. 2018.

STENHOUSE, L.The humanities project: An introduction. London: Heinemann, 1970.

VYGOTSKY, Lev S. A formação social da mente. São Paulo: Martins Fontes, 1984.

ZEILDLER, D. L.; NICHOLS, B.H.; Socioscientific Issues: theory and practice. Journal of Elementary Science Education, v. 21, n. 1, p.49-58. 2009.

ZIMAN, J. Teaching and Learning About Science and Society. Cambridge: Cambridge University Press, 1980.

Recebido em julho de 2020.

Aprovado em novembro de 2020. 